\title{
S1 Instrument
}

\section{流行病學研究中心抑桓量表 \\ The Center for Epidemiologic Studies Depression Scale (CES-D)}

以下句子描述一些自我感覺或行為。請圈出最接近您過去一週的狀況。

Below is a list of some of the ways you may have felt or behaved. Please indicate how often you have felt this way during the past week: (circle one number on each line)

\section{過去一週}

During the past week...

1. 我被一些平時不會困擾我的事情困擾 I was bothered by things that usually don't bother me

2. 我不想吃東西, 我的胃口很差 I did not feel like eating; my appetite was poor

3. 即使有家人和朋友的幫忙, 我仍然

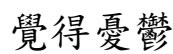

I felt that I could not shake off the blues even with help from my family

4. 我覺得我不比其他人差

I felt that I was just as good as other people

5. 我很難集中精神工作

I had trouble keeping my mind on what I was doing

6. 我覺得情緒低落 I felt depressed

7. 我覺得我做每件事情都很吃力 I felt that everything I did was an effort

8. 我對將來抱有希望 I felt hopeful about the future

9. 我覺得自己一生很失敗 I thought my life had been a failure

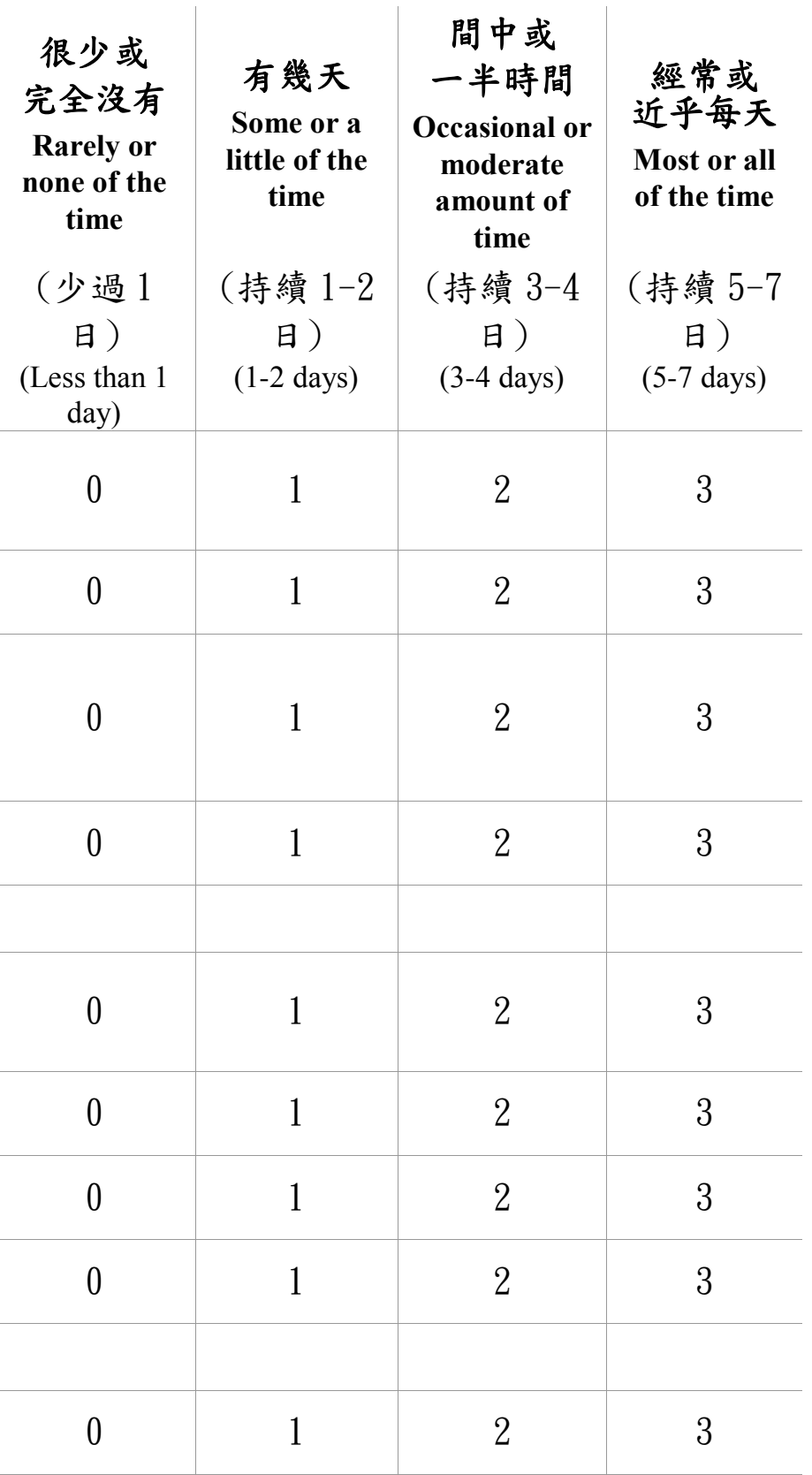


Page $\mathbf{2}$ of $\mathbf{2}$

\begin{tabular}{|c|c|c|c|c|}
\hline $\begin{array}{l}\text { 10. 我覺得恐懼 } \\
\text { I felt fearful }\end{array}$ & 0 & 1 & 2 & 3 \\
\hline $\begin{array}{l}\text { 11. 我睡眠不安寧 } \\
\text { My sleep was restless }\end{array}$ & 0 & 1 & 2 & 3 \\
\hline $\begin{array}{l}\text { 12. 我很開心 } \\
\text { I was happy }\end{array}$ & 0 & 1 & 2 & 3 \\
\hline $\begin{array}{l}\text { 13. 我比平時少說話 } \\
\text { I talked less than usual }\end{array}$ & 0 & 1 & 2 & 3 \\
\hline $\begin{array}{l}\text { 14. 我覺得孤獨 } \\
\text { I felt lonely }\end{array}$ & 0 & 1 & 2 & 3 \\
\hline $\begin{array}{l}\text { 15. 我覺得其他人不友善 } \\
\text { People were unfriendly }\end{array}$ & 0 & 1 & 2 & 3 \\
\hline $\begin{array}{l}\text { 16. 我很享受生活 } \\
\text { I enjoyed life }\end{array}$ & 0 & 1 & 2 & 3 \\
\hline $\begin{array}{l}\text { 17. 我會經常無故哭泣 } \\
\text { I had crying spells }\end{array}$ & 0 & 1 & 2 & 3 \\
\hline $\begin{array}{l}\text { 18. 我覺得不開心 } \\
\text { I felt sad }\end{array}$ & 0 & 1 & 2 & 3 \\
\hline $\begin{array}{l}\text { 19. 我覺得其他人不喜歡我 } \\
\text { I felt that people disliked me }\end{array}$ & 0 & 1 & 2 & 3 \\
\hline $\begin{array}{l}\text { 20. 我提不起勁 } \\
\text { I could not get "going" }\end{array}$ & 0 & 1 & 2 & 3 \\
\hline
\end{tabular}

